\title{
“... Every End Is a Beginning, Every Beginning Is an End ...": Thank You and Good-Bye to Karin Kraft, Frauke Musial, and Benno Brinkhaus
}

\author{
Harald Walach ${ }^{a, b, c}$ \\ ${ }^{a}$ Department of Pediatric Gastroenterology, Poznan University of Medical Sciences, Poznan, Poland; ${ }^{b}$ Department \\ of Psychology, University of Witten/Herdecke, Witten, Germany; ${ }^{\mathrm{C} C h a n g e ~ H e a l t h ~ S c i e n c e s, ~ B e r l i n, ~ G e r m a n y ~}$
}

"... Every end is a beginning, every beginning is an end ..."

Those words from T.S. Eliots "Four Quartets" came to my mind when I settled to the task, joyful and sad, of saying good-bye and thanking three of our long-term associate editors who are leaving us this term for various reasons: Karin Kraft, Frauke Musial, and Benno Brinkhaus.

It is not possible to do them and their effort justice in the brief space of an editorial, but try I must nevertheless. All of them have been intimately associated with our journal: Karin Kraft since 1999, thus nearly from the beginning, and Frauke Musial and Benno Brinkhaus since 2009. It is important to remind everyone that this is a voluntary service to the community - to the smaller community of complementary medicine researchers and the larger scientific community of readers and authors. None of us editors receive a benefit or reward other than a joint meal sponsored by the publisher at our annual editorial board meeting. The benefit and the reward are intrinsic - mostly: being able to shape the communication of authors of the research community to the public, by being a gatekeeper for papers that are worth publishing and those that are not - in our eyes anyway. But it is also the option to help younger writers to come out with their findings, by spotting talents among those submitting to the journal, even when the writing or the presentation is less than perfect at first sight. It is the option to shape the presentation of the field in the public eye: what is per- ceived as potentially important, how research should be conducted, what topics are covered and belong to the field, what type of information needs to be presented, what is undisputedly part of our field.

Karin Kraft will stay very much present in our common perception as a guarantor of good research practice in phytotherapy. She has always impressed me by her encyclopedic knowledge when it comes to plants, paired with an angel-like patience with all those who do not know better and ask silly questions, like me. Few people know that she had to recruit the money for her position herself several times and run for the next grilling with a less than friendly committee in Rostock, where some of her colleagues would not have minded if the topic of natural medicine had vanished in the depths of the Baltic sea, if I read some of her comments correctly. That in itself is a feat and a testimony to her valiance that went unbent and unbeaten whenever it came to fights and standing up for her views. That is the reason, I guess, why she will rather work behind the scenes, in various committees, be they guideline committees or still more arcane ones. In that sense, the ending of Karin Kraft's term is clearly a beginning. Now she has more time for debates in committees and meetings, and, nomen est omen, more power as well. 
Frauke Musial has moved from Essen, where she was part of Gustav Dobos's group for many years, to the northernmost part of academia in this world, to Tromsø, beyond the polar circle, where she took up a position as a professor and research leader. The Norwegian government had established what is probably the best-funded and longest-lasting research center in complementary medicine in Europe, if not worldwide. I have been invited to Tromsø by NAFKAM's former director, Vinjar Fonnebø, various times and can understand how, once you are there, you are captivated by a fascinating landscape and how every attempt at getting somewhere else is a major effort. The distance from northern Norway to Oslo is just about as far as from northern Germany to southern Italy, and then you have to catch another flight. Norway has received various new policies of various codes of political correctness, one of which is that researchers have to publish open access and that researchers have to invest effort in journals that do. Frauke Musial supported our journal nevertheless and I am sure she would have done so, despite the codes active in her country of residence, if not other tasks of supervising research together with a compression of time and effort in the face of ever-growing demands had prevented her. Frauke Musial was always a safe haven for papers with unusual topics, designs, or findings. Her deep knowledge in pain and various psychological and complementary medical techniques was a real pillar in the editorial team. We will miss her very much, but here as well, the ending is a new beginning: NAFKAM has a new director, there is a new effort in that center to move CAM research forward, and this will keep Frauke busy, I am sure, together with her horses.

I remember Benno as a very young doctor with Erlangen internal medicine unit in one of our very first meetings of the forum of academic research centers in CAM in Germany. This must have been in the early 1990s. Al- ready then was visible what came to the fore later: a very diligent, extremely bright and eager researcher who was willing to bear the burden of medical hierarchies above as if they were a light enlivening breeze sent from God on high, despite the often visible effects to the contrary. Benno was virtually one of the handful of researchers who secured research funding from the German Research Council for a study on acupuncture, going through the nitty-gritty of obviously less than competent reviewers' remarks, adapting his design and proposal, bowing down to renewed remarks and all the hoops of academic power games before you can use the taxpayer's money for research that the reviewers had to grudgingly admit might be good. It was in that spirit that he secured not only research money, but a professorship for himself, and strengthened the team at the Charité. Benno was always a beacon for high research and paper quality. Benno Brinkhaus has a lot of other stuff to manage: his professorship was prolonged, he has to do high-quality research at another pace than most of us to be able to survive in a highly competitive environment at the Charite at a time, where its CAM outpatient department is prohibited from advertising the full range of their methods for fear of becoming attacked by skeptics at the inside and from the outside. So, what for him this ending will be in terms of new beginning I do not really know, but I am sure we will see sooner than later for ourselves.

And so I can only, once again, publicly, from the depths of my heart and on behalf of the whole editorial team, say: thank you to you all and may your paths take you forward, to more fullness and some lightness of heart.

\section{Conflict of Interest Statement}

I have no conflict of interest. 